\title{
MODELING OF RAW CANE-SUGAR SYRUP CONCENTRATION USING DIRECT CONTACT MEMBRANE DISTILLATION
}

\author{
Ali K. Abdel-Rahman \\ Associate Professor, Department of Mechanical Engineering Faculty \\ of Engineering, Assiut University, Assiut 71516, EGYPT \\ E-mail: nada ali54@yahoo.com
}

(Received June 21, 2008 Accepted August 25, 2008)

Membrane distillation is an emerging technology for separations that are traditionally accomplished by conventional separation processes such as distillation and reverse osmosis. The membrane distillation driving force is the transmembrane vapor pressure difference that may be maintained with an aqueous solution colder than the feed solution in direct contact with the permeate side of the membrane giving rise to the configuration known as direct contact membrane distillation (DCMD). This process is ideally suited for the concentration of aqueous streams such as fruit juice and sugar solutions.

The present numerical study is carried out to describe how the technique of DCMD can be applied to the concentration of cane-sugar syrup. The main objective of the present study is to provide a detailed numerical analysis of the heat and mass transfer in DCMD and to offer useful basic detailed information about the nature of the process that is needed for process improvement and optimization. In this regards, the present study is carried out to explore the effects of parameters such as the feed temperature, the feed concentration and the hydrodynamics of the hot and cold solutions on the distillate volume flow.

The developed method allows solving numerically the hydrodynamic, heat and mass transport equations with permeation taken into account. Velocity and temperature distributions inside the membrane feed and cold solution channels were obtained, as well as the concentration profiles of the cane-sugar syrup in the membrane feed channel. Some of the principal conclusions drawn from the present study are: (1) the distillate volume flux increases with the feed temperature, (2) the distillate volume flow decreases as the feed initial concentration increases, and (3) the distillate volume flow increases with the flow rate through the feed channel. The results were compared with the available data and the agreement is satisfactory.

KEYWORDS: Membrane distillation; Direct contact membrane distillation; Modeling; Cane-sugar syrup, Concentration. 


\section{NOMENCLATURE}

$\begin{array}{ll}\text { Alphabetic Symbols } \\ c & \text { concentration }(\mathrm{kg} / \mathrm{kg}) \\ c_{p} & \text { specific heat capacity }(\mathrm{kJ} / \mathrm{kg} \mathrm{K}) \\ D_{s} & \text { solute diffusion coefficient }\left(\mathrm{m}^{2} / \mathrm{s}\right) \\ H & \text { channel height }(\mathrm{m}) \\ J_{v} & \text { mass flux }\left(\mathrm{kg} / \mathrm{m}^{2} . \mathrm{s}\right) \\ k_{s} & \text { solute thermal conductivity }(\mathrm{W} / \mathrm{m} \mathrm{K}) \\ L & \text { channel length }(\mathrm{m}) \\ p & \text { pressure }(\mathrm{Pa}) \\ S_{\Phi} & \text { source term of the variable } \phi \\ S_{p} & \text { coefficient in the discretized source } \\ & \text { term } \\ S_{u} & \text { coefficient in the discretized source } \\ & \text { term } \\ T & \text { temperature }\left({ }^{\circ} \mathrm{C}\right) \\ u & \text { streamwise velocity }(\mathrm{m} / \mathrm{s}) \\ v & \text { velocity in } y \text { direction }(\mathrm{m} / \mathrm{s}) \\ x & \text { Cartesian coordinate in the } \\ & \text { streamwise direction }\end{array}$

y Cartesian coordinate normal to the membrane

\section{Greek Symbols}

$\delta \quad$ membrane thickness (m)

$\varepsilon \quad$ membrane porosity (\%)

$\phi \quad$ any of variables to be solved

$\Gamma_{\Phi} \quad$ diffusion coefficient of variable $\phi$

$\mu \quad$ dynamic viscosity (Pa .s)

$v \quad$ kinematics viscosity $=\mu / \rho\left(\mathrm{m}^{2} / \mathrm{s}\right)$

$\rho$ density $\left(\mathrm{kg} / \mathrm{m}^{3}\right)$

$\tau$ membrane tortuosity

\section{Subscripts}

$\begin{array}{ll}b & \text { bulk } \\ h & \text { hot stream } \\ i & \text { inlet } \\ c & \text { cold stream } \\ m & \text { membrane } \\ s & \text { solute, or solid }\end{array}$

\section{INTRODUCTION}

Membrane distillation (MD) is an emerging technology for separations that are traditionally accomplished by conventional separation processes such as distillation or reverse osmosis. Since its appearance, MD claims to be a cost effective separation process that can utilize low-grade waste and/or alternative energy sources such as solar and geothermal energies. The potential advantages of MD process in comparison to the conventional separation processes rely on the lower operating temperature and hydrostatic pressure. Feed solutions having temperatures much lower than its boiling point under pressures near atmosphere can be used.

Direct contact membrane distillation (DCMD), in which two solutions at different temperatures are in direct contact with the membrane surfaces, appears as the best configuration for applications in which the major feed component is water, such as desalination and concentration of aqueous solutions. DCMD has found success in areas where treatments at lower temperatures are preferred over that at higher temperatures in order to safeguard product quality $[1,2]$. DCMD was also investigated for desalination applications. Some studies $[3,4]$ were carried out to produce fresh water with a rejection factor of $100 \%$.

In a conventional cane sugar manufacturing process [5], the clarified juice (17$20^{\circ}$ Brix) which comes as an overflow from the Dorr at a temperature of about $100^{\circ} \mathrm{C}$ proceeds either to a rising film evaporator (Kestner) or a falling film evaporator (calandria) of the vertical /horizontal type. The falling film evaporator (calandria) is operated with steam $\left(135^{\circ} \mathrm{C}\right.$, and $\left.2.1 \mathrm{~kg} / \mathrm{cm}^{2}\right)$. From here the juice goes to a multi- 
effect evaporator. The consumption of steam for the removal of water from this juice is considerable. If one were to put a membrane distillation step before the juice goes to the evaporators, it is technically feasible to increase the solids in juice from $17^{\circ}$ to $30^{\circ}$ Brix. The numerical study was carried out to simulate this step.

As an attractive separation process, MD has been the subject of worldwide academic studies by many experimentalist and theoreticians [e.g. 1-4]. Recently, Sanjay Nene et al. [6] applied DCMD for the concentration of raw cane-sugar syrup. They pointed out that it's technically feasible to introduce a membrane distillation step to increase the solids in juice from 17 to $30^{\circ}$ Brix. The aim of their experiments was to study the flux decay in membrane distillation when the run conditions were similar to those in the sugar industry. The obtained results indicate that it is possible to continuously remove water from the cane sugar solution at steady-state value with the capacity of about $10.0 \mathrm{~kg} / \mathrm{m}^{2} \mathrm{~h}$. They also claimed that MD saves energy in removing water from clarified cane juice by utilizing sensible heat.

Computational fluid dynamics (CFD), together with mass transfer modeling, has been proved to be a powerful tool to be used in the feed and permeate sides of membrane modules to effect the predictions of velocities, pressure, temperature and solute concentration, variables that are crucial for the management of the syrup concentration process. The present study pertains to modeling numerically of a canesugar syrup concentration using DCMD. The study is directed towards establishing a numerical method capable of predicting the flow and concentration characteristics of the DCMD taking into account the variable properties of the streams. For this purpose, a finite volume discrete scheme using the SIMPLE (Semi-Implicit Method for Pressure Linked Equations) pressure-correction scheme combined with QUICK (Quadratic Upwind Interpolation Convective Kinematics) scheme in the frame of staggered grid is used.

The present numerical study is carried out to describe how the technique of DCMD can be applied to the concentration of cane-sugar syrup. The main objective of the present study is to provide a detailed numerical analysis of the heat and mass transfer in DCMD and to offer useful basic detailed information about the nature of the process that is needed for process improvement and optimization. In this regards, the present study is carried out to explore the effects of parameters such as the feed temperature, the feed concentration and the hydrodynamics of the hot and cold solutions on the distillate volume flow.

\section{MODEL DEVELOPMENT}

The system to be studied consists of a porous hydrophobic membrane, which is held between two symmetric channels shown in Fig. 1. The configuration is similar to a heat exchanger working in counter-current flow with the warm cane-sugar syrup solution flowing in the lower channel and the cold water solution on the upper side of the membrane module. Mass and heat balance equations were written to describe the concentration and temperature profiles on both the hot and cold sides. The hot and cold fluids counter-flow tangentially to the membrane surface in a flat membrane module. The temperature difference through the membrane gives rise to a water vapor pressure difference and, consequently to a water flux, $J$, through the membrane. The process is 
modeled by solving the 2-dimentional momentum, energy and species equations in the hot and cold solutions regions.

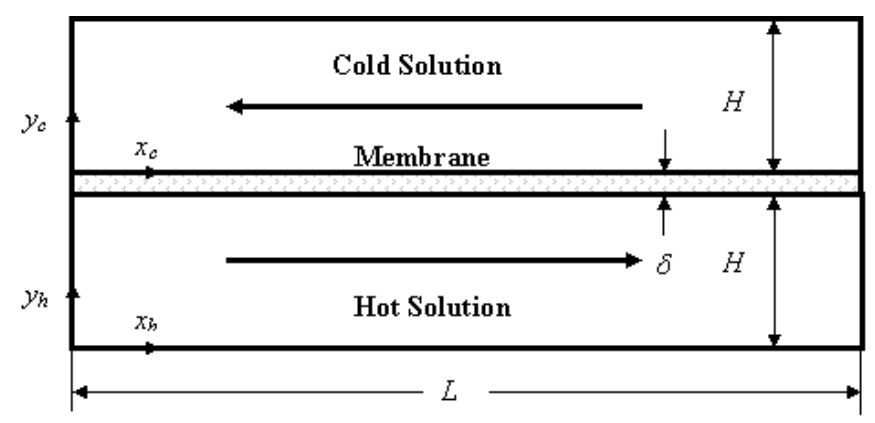

Fig. 1 Membrane module including the membrane and the hot and cold solutions channels

\subsection{The Hot Solution Region}

The hot syrup solution flows between two parallel walls, the upper wall is hydrophobic microporous membrane and the lower one is impermeable wall. The transport steady state, two dimensional transports of the momentum, energy, and species of the hot solution are described by the continuity, momentum, energy and species conservation equations [7];

$$
\frac{\partial u_{h}}{\partial x_{h}}+\frac{\partial v_{h}}{\partial y_{h}}=0
$$

$\frac{\partial\left(\rho_{s} u_{h} u_{h}\right)}{\partial x_{h}}+\frac{\partial\left(\rho_{s} v_{h} u_{h}\right)}{\partial y_{h}}-\frac{\partial}{\partial x_{h}}\left[\mu_{s}\left(\frac{\partial u_{h}}{\partial x_{h}}\right)\right]-\frac{\partial}{\partial y_{h}}\left[\mu_{s}\left(\frac{\partial u_{h}}{\partial y_{h}}\right)\right]+\frac{\partial P_{h}}{\partial x_{h}}=0$

$$
\frac{\partial\left(\rho_{s} u_{h} v_{h}\right)}{\partial x_{h}}+\frac{\partial\left(\rho_{s} v_{h} v_{h}\right)}{\partial y_{h}}-\frac{\partial}{\partial x_{h}}\left[\mu_{s}\left(\frac{\partial v_{h}}{\partial x_{h}}\right)\right]-\frac{\partial}{\partial y_{h}}\left[\mu_{s}\left(\frac{\partial v_{h}}{\partial y_{h}}\right)\right]+\frac{\partial P_{h}}{\partial y_{h}}=0
$$

Where, $u_{h}$ and $v_{h}$ are the streamwise and transverse velocity components of the hot solution, respectively, $P$ is the pressure, $\rho$ is the density and $\mu$ is the dynamic viscosity.

Mass transfer occurring within domains with porous walls can be mathematically expressed by the two dimensional convective and diffusion equation as follows [8];

$$
\frac{\partial\left(\rho_{s} u_{h} c_{s}\right)}{\partial x_{h}}+\frac{\partial\left(\rho_{s} v_{h} c_{s}\right)}{\partial y_{h}}-\frac{\partial}{\partial x_{h}}\left[D_{s}\left(\frac{\partial c_{s}}{\partial x_{h}}\right)\right]-\frac{\partial}{\partial y_{h}}\left[D_{s}\left(\frac{\partial c_{s}}{\partial y_{h}}\right)\right]=0
$$

Where $D_{s}$ is the solute diffusion coefficient and $c_{s}$ is the solute concentration.

Most of the previous models solve equations (1)-(4) using constant or concentration-dependent only thermophysical and flow properties. In the present study, the energy equation has to be solved to account for the temperature dependence of the abovementioned properties. For two dimensional, incompressible, steady laminar channel flow; the energy equation is given as [8] 


$$
\frac{\partial\left(\rho_{s} u_{h} T_{h}\right)}{\partial x_{h}}+\frac{\partial\left(\rho_{s} v_{h} T_{h}\right)}{\partial y_{h}}-\frac{\partial}{\partial x_{h}}\left[\frac{k_{s}}{c_{p s}}\left(\frac{\partial T_{h}}{\partial x_{h}}\right)\right]-\frac{\partial}{\partial y_{h}}\left[\frac{k_{s}}{c_{p s}}\left(\frac{\partial T_{h}}{\partial y_{h}}\right)\right]=0
$$

where $k_{s}$ and $c_{p s}$ are the hot solution thermal conductivity and specific heat at constant pressure, respectively.

\subsection{The Membrane Domain}

In DCMD the pressure difference at two sides of the membrane will be zero when both the feed and permeate flows are under atmospheric pressure. In this case the contribution of Poiseuille flow to mass transfer can be neglected. At the typical membrane temperature of $60{ }^{\circ} \mathrm{C}$, the mean free path of water vapor is $0.11 \mu \mathrm{m}$ and the mean pore diameter of membranes is $0.1-0.5 \mu \mathrm{m}$. Therefore, in the system where water (component $\mathrm{A}$ ) is used as volatile component $\mathrm{Kn}$ (Knudsen number) may vary from 0.2 to 1.0. As air (component B) is trapped in the pores, the permeation of water vapor through the membrane is regulated by the Knudsen-molecule diffusion transition mechanism.

For mass transfer through the membrane in DCMD, on the ground of Knudsen-molecule diffusion transition model, the following equation can be obtained to calculate trans-membrane mass flux, $J_{v}[9]$ :

$$
J_{v}(x)=\frac{\varepsilon M_{A}}{\tau \delta} \frac{p D_{A B}}{R T_{m}} \ln \frac{\left(p-p_{p m}\right) / p D_{A B}+(3 / 4 d) \sqrt{2 \pi M_{A} / R T_{m}}}{\left(p-p_{f m}\right) / p D_{A B}+(3 / 4 d) \sqrt{2 \pi M_{A} / R T_{m}}}
$$

where $\varepsilon$ (porosity), $\delta$ (thickness), $d$ (pore diameter) and $\tau$ (tortuosity), are membrane geometry parameters, $T_{m}$ is the hot and cold streams average temperature $(\mathrm{K}), R$ is the universal gas constant, $M_{A}$ is the water vapor molecular weight, $p_{p m}$ and $p_{f m}$ are the vapor partial pressures $(\mathrm{Pa})$ at the membrane-permeate and feed interfaces respectively calculated by using [4]:

$$
p^{v}=\exp \left(23.328-\frac{3841}{T-45}\right)
$$

$p$ the total (air + vapor) pressure, and $D_{\mathrm{AB}}$ is the diffusion coefficient of the vapor through the air $\left(\mathrm{m}^{2} / \mathrm{s}\right)$ at the temperature of $273-373 \mathrm{~K}$ which is estimated from the following empirical equation [4]:

$p D_{A B}=1.895 \times 10^{-5} \mathrm{~T}^{2.072}$

where the unit of $p D_{A B}$ is $\mathrm{Pa}-\mathrm{m}^{2} / \mathrm{s}$.

On the other hand, the resistances in the heat transfer process of DCMD consist of three parts: the resistance of boundary layer at the feed side, of the membrane and of the boundary layer at the permeate side. The total heat flux is transferred from the hot surface of the membrane to the cold surface of the membrane by two different parallel routes. One is by heat conduction across the membrane material $\left(Q_{\mathrm{C}}\right)$ while the other is by the mass transfer of the vapor $\left(Q_{L}\right)$ 
$Q_{T}=Q_{L}+Q_{C}=J_{v} \Delta H_{v}+\left(k_{m} / \delta\right)\left(T_{f m}-T_{p m}\right)$

where $\Delta H_{v}$ is the latent heat of vaporization. In Eq. (9) $k_{m}$ is the thermal conductivity of the porous membrane that can be calculated as

$k_{m}=\varepsilon k_{g}+(1-\varepsilon) k_{s}$

with $k_{g}$ and $\mathrm{k}_{\mathrm{s}}$ being the thermal conductivities of the gas and solid phases [10].

\subsection{The Cold Solution Region}

The cold solution flows between two parallel walls, the lower wall is hydrophobic microporous membrane and the upper one is impermeable wall. The transport of the momentum and energy of the cold solution are described by the continuity, momentum, and energy conservation equations [7];

$$
\begin{aligned}
& \frac{\partial u_{c}}{\partial x_{c}}+\frac{\partial v_{c}}{\partial y_{c}}=0 \\
& \frac{\partial\left(\rho_{w} u_{c} u_{c}\right)}{\partial x_{c}}+\frac{\partial\left(\rho_{w} v_{c} u_{c}\right)}{\partial y_{c}}-\frac{\partial}{\partial x_{c}}\left[\mu_{w}\left(\frac{\partial u_{c}}{\partial x_{c}}\right)\right]-\frac{\partial}{\partial y_{c}}\left[\mu_{w}\left(\frac{\partial u_{c}}{\partial y_{c}}\right)\right]+\frac{\partial P_{c}}{\partial x_{c}}=0 \\
& \frac{\partial\left(\rho_{w} u_{c} v_{c}\right)}{\partial x_{c}}+\frac{\partial\left(\rho_{w} v_{c} v_{c}\right)}{\partial y_{c}}-\frac{\partial}{\partial x_{c}}\left[\mu_{w}\left(\frac{\partial v_{c}}{\partial x_{c}}\right)\right]-\frac{\partial}{\partial y_{c}}\left[\mu_{w}\left(\frac{\partial v_{c}}{\partial y_{c}}\right)\right]+\frac{\partial P_{c}}{\partial y_{c}}=0
\end{aligned}
$$

Where, $u_{c}$ and $v_{c}$ are the streamwise and transverse velocity components of cold stream, respectively, $P$ is the pressure, $\rho$ is the density and $\mu$ is the dynamic viscosity.

In the present study, the energy equation has to be solved to account for the temperature dependence of the cold stream properties. For two dimensional, incompressible, steady laminar channel flow; the energy equation is given as [8]

$$
\frac{\partial\left(\rho_{w} u_{c} T_{c}\right)}{\partial x_{c}}+\frac{\partial\left(\rho_{w} v_{c} T_{c}\right)}{\partial y_{c}}-\frac{\partial}{\partial x_{c}}\left[\frac{k_{w}}{c_{p w}}\left(\frac{\partial T_{c}}{\partial x_{c}}\right)\right]-\frac{\partial}{\partial y_{c}}\left[\frac{k_{w}}{c_{p w}}\left(\frac{\partial T_{c}}{\partial y_{c}}\right)\right]=0
$$

where $k_{w}$ and $c_{p w}$ are the cold solution thermal conductivity and specific heat at constant pressure, respectively.

\subsection{Boundary Conditions}

The boundary conditions of the problem are specified as the followings:

1- At the inlet of both channels, the flow is assumed to be fully developed thus a parabolic flow is specified. A uniform inflow concentration of $c_{s b}$ is specified at the inlet of the hot solution channel. A constant inlet temperature of $T_{h b}$ and $T_{c b}$ are specified at the inlet of the hot and cold channels, respectively.

2- At the lower wall of the hot channel, the tangential velocity $u$ and the transverse velocity $v$ are set to zero; the normal gradients of the concentration and temperature are set to zero. 
3- At the upper wall of the cold channel, the tangential velocity $u$ and the transverse velocity $v$ are set to zero; the normal gradients of the temperature are set to zero.

4- At the membrane walls, the conditions are more complex, as flow permeates through the wall. The tangential velocity $u$ is set to zero i.e. no slip at membrane walls. Variation in permeation was modeled using the following expression;

$$
v_{m h}(x)=J_{v}(x) / \rho_{s},
$$

The boundary condition of the concentration at the membrane lower wall results from a balance of the convective and diffusive fluxes. The concentration boundary condition is given by;

$$
\left.D_{s} \frac{\partial c_{s}(x)}{\partial y}\right|_{y=H}=J_{v}(x) / \rho_{s}
$$

The boundary condition of the temperature at the membrane walls results from a balance of the convective and conductive heat fluxes. The temperature boundary condition is given by;

$$
-\left.k_{s} \frac{\partial T(x)}{\partial y}\right|_{y=0 o r H}=Q_{C}(x)+J_{v}(x) \Delta H_{v}
$$

5- At the exit, both the flow, temperature and concentration fields are assumed to obey the boundary layer approximation. It is important to mention that this treatment of the down stream end boundary condition has proved to be robust and effective in shortening the computational domain leading to the reduction of the number of grid nodes [11].

\subsection{Discretization}

The steady-state form of the conservation equations of continuity, momentum, concentration and energy can be written in a general form as [12];

$$
\frac{\partial(\rho u \phi)}{\partial x}+\frac{\partial(\rho v \phi)}{\partial y}-\frac{\partial}{\partial x}\left[\Gamma_{\phi}\left(\frac{\partial \phi}{\partial x}\right)\right]-\frac{\partial}{\partial y}\left[\Gamma_{\phi}\left(\frac{\partial \phi}{\partial y}\right)\right]-S_{\phi}=0
$$

where $\phi$ stands for any of the variables to be solved, $\Gamma_{\Phi}$ is the diffusion coefficient, and $S_{\Phi}$ is the source term of the variable $\phi$. For $\phi=u$ or $v$ and $\Gamma_{\Phi}=\mu$ one gets the momentum equations, while for $\phi=1$ and $\Gamma_{\Phi}=0$ one obtains the continuity equation [13]. If $\phi=T$ and $\Gamma_{\Phi}=k_{\ell} / c_{p}$ one gets the energy equation. When $\phi=c$ and $\Gamma_{\Phi}=D$, the general equation stands for the mass transfer equation [14].

All the governing equations are discretized by first integrating them over a control volume (CV) and then approximating the fluxes of variable crossing the faces of each cell in terms of the values at the neighboring grid points. In the present work, a QUICK scheme, which can handle uniform and non-uniform grid systems, is used to 
finite differencing the convective terms and to secure second order accuracy in central differencing the diffusive fluxes. The resulting finite-difference equations are described in the form of [15],

$$
\begin{array}{ll}
a_{p} \phi_{p}=\sum_{i} a_{i} \phi_{i}+S_{u} \Delta V, & i=E, W, N, S, E E, W W, N N, S S, \\
a_{p}=\sum_{i} a_{i}-S_{p} \Delta V, & i=E, W, N, S, E E, W W, N N, S S,
\end{array}
$$

where $\Delta V$ is the cell volume and $S_{p}$ and $S_{u}$ are the coefficients appearing in the following linearized source term;

$$
S_{\phi}=S_{u}+S_{p} \phi
$$

The finite difference coefficients $a_{i}$ are the coefficients describing the magnitudes of the sum of the convective and diffusive fluxes and contain the geometric properties of the control volume [11].

\subsection{Numerical Procedure}

The present study utilizes a modified version of the SIMPLE procedures developed by Partaker and Spalding [15]. The main steps of the SIMPLE algorithm are;

1- A pressure field is assumed in the hot channel,

2- It is used to obtain approximate velocity field in the hot channel,

3- The velocity and pressure fields (in the hot channel) are corrected if the former does not satisfy the continuity equation,

4- Solve the discretization equations for the other $\phi$ 's such as temperature and concentration (in the hot channel) provided their influence on the flow field.

5- Do step 1-4 in the cold channel. Calculate the membrane permeation and heat transfer through the membrane.

6- Return to step 2 with the corrected velocity field and the new values of all other $\phi$ 's and then the steps 2-5 are repeated until a converged solution is obtained.

In the present work, the cross-stream distribution of $u$-velocity component is adjusted to satisfy the overall continuity (conservation of the mass flow are integrated over a cross-stream line) whereas the pressure field is adjusted to satisfy the overall momentum balance. This procedure is important especially for the present problem in which the flow is changed as the flow moves downstream due to the permeation through the membrane surface $[11,13]$. Moreover, the cross-stream distribution of the concentration (in the hot channel) is adjusted to satisfy the overall mass concentration of the permeated species.

An alternating direction implicit (ADI) procedure has been combined with the iterative solution procedure of equations (15) to enhance isotropic propagation of a change of variables occurring at one point to the surrounding [13]. This procedure makes use of the line-by-line TDMA solver. In the ADI procedure, sweep of line- byline integration was carried out along both north-south grid lines and along east-west grid lines alternatively. The same procedure was applied twice for the pressure correction [11]. 


\subsection{Physical Properties}

The membrane solute rejection leads to the development of a solute concentration profile in the hot fluid phase adjacent to the membrane. The hot stream was a pure sucrose solution with a concentration corresponding to the raw cane juice. Expressions for the variation of physical properties with temperature and concentration for sugar solution were taken from sugar technologist manual [16]. The cold stream was liquid water subjected to temperature variations. Therefore, the transport and physical properties of the solutions, in the transport equations (1)-(13), should include the variation with the solute concentration (in the hot stream) and the solution temperature in both cold and hot streams. The correlations relative to the variation with the temperature of the physical and transport properties of the liquid water were collected from different sources [e.g. 17].

\section{PROCESS PARAMETERS}

The parameters to be evaluated in this work include the averaged permeate flux, the conductive heat transfer, the total heat transfer, the process thermal efficiency.

The averaged permeate flux is obtained by integrating Eq. (6) over the length of the membrane and dividing by the membrane length $(L)$

$J=\frac{1}{L} \int_{0}^{L} J_{v}(x) d x$

by integrating the second term of Eq. (9), the $x$-averaged conduction heat flux is

$Q_{C}=\frac{1}{L} \int_{0}^{L} Q_{C}(x) d x$

by integrating the first term of Eq. (9), the $x$-averaged latent heat flux is

$Q_{L}=\frac{1}{L} \int_{0}^{L} Q_{L}(x) d x$

and by integrating Eq. (9), the total heat transfer is

$Q_{T}=\frac{1}{L} \int_{0}^{L} Q_{T}(x) d x$

The process thermal efficiency can be defined as

$\eta_{t h}=\frac{Q_{L}}{Q_{T}}$

where the numerator is the heat used for the production of the distillate.

Polarization phenomena can be described using a temperature polarization coefficient (TPC) and a concentration polarization coefficient (CPC), defined as [1]:

$$
\begin{aligned}
& T P C=\frac{1}{L} \int_{0}^{L} \frac{T_{m h}(x)-T_{m c}(x)}{T_{b h}(x)-T_{b c}(x)}, \\
& C P C=\frac{1}{L} \int_{0}^{L} \frac{c_{m h}(x)-c_{m c}(x)}{c_{b h}(x)-c_{b c}(x)}=\frac{1}{L} \int_{0}^{L} \frac{c_{m h}(x)}{c_{b h}(x)}
\end{aligned}
$$


where ' $\mathrm{m}$ ' and ' $\mathrm{b}$ ' indicate the values of temperature and concentration on the membrane surface and in the bulk condition, respectively.

\section{RESULTS AND DISCUSSION}

\subsection{Model Validation}

The computations are carried out in the rectangular domain shown in Fig. 1. The main results were obtained for computational domain of $H=0.45 \times 10^{-3} \mathrm{~m}, L=0.1 \mathrm{~m}$. The membrane employed in this study has the characteristics of 0.8 porosity $(\varepsilon)$, a nominal pore size $\left(d_{p}\right)$ of $0.2 \mu \mathrm{m}$, thermal conductivity $\left(k_{m}\right)$ of $0.055 \mathrm{~W} / \mathrm{m} \mathrm{K}$, and thickness $\left(\delta_{\mathrm{m}}\right)$ of $0.6 \times 10^{-4} \mathrm{~m}$. A grid-dependence analysis of the method of solution was performed. The number of elements is chosen to be $16,000(400 \times 40)$ because further refinement of the mesh to 24,000 elements produced just a $0.06 \%$ difference in $J$.

Moreover, to ensure that the numerical solution is not affected adversely by the specification of the inlet conditions to the hot and cold liquid flow channels, the sensitivity of the solution to the location where the inlet boundary conditions were specified was investigated. Comparing the velocity distributions for specifying the inlet at a distance of $x / H=100$ upstream of the channels' inlets (Fig. 1), and for specifying them at the inlet itself $(x / H=0)$, has shown no discernible differences.

On the light of the objective of the present work, the validity of the present numerical simulation has been verified by comparing results of the present study with the existing experimental data of Martinez-Diez and Vazquez-Gonzalez [18]. Figure 2 shows the average permeate fluxes predicted by the present model along with the experimental data of Martinez-Diez and Vazquez-Gonzalez [18]. In Fig. 2 the distillate fluxes for the three recirculation rates studied (feed and permeate average velocities of 25,39 , and $53 \mathrm{~m} / \mathrm{s}$ ) are displayed as a function of the imposed temperatures when distilled water is used as feed. A non-linear increase in the flux, as shown in Fig. 2, with increasing temperature reflects the exponential increase in the vapor pressure which provides the driving force. Figure 2 also shows that the permeate flux increases when the recirculation rate is increased. The effect of a higher recirculation rate is to increase the heat transfer coefficient and thus reduce the effect of temperature polarization. This means that the temperatures at the membrane surface more closely approximate that of the bulk streams, and thus the transmembrane temperature difference is greater. This produces a greater driving force and consequently enhances the flux. The figure shows that the present model is capable of predicting permeate fluxes with a reasonable accuracy.

The phenomenon of the temperature polarization causes the temperatures at the membrane surfaces to differ from the bulk temperatures measured in the feed and in the distillate. This phenomenon is present even when the feed is water and causes an important loss in the driving force for transport with regard to the imposed force. The corresponding temperature polarization coefficients $(T P C)$ are calculated using the present numerical study and compared with the results obtained by Diez and VazquezGonzalez [18]. These results are shown in Fig. 3 which indicates that the present model is capable of predicting TPC with a reasonable accuracy. The results shown in Fig. 3 suggest that the $T P C$ is an important factor affecting the mass flux as TPC values range between 0.4 and 0.6. Moreover, in the temperature interval studied ( $T_{b h}$ varied from 
$20^{\circ} \mathrm{C}$ to $50^{\circ} \mathrm{C}$ ), $T P C$ varied significantly, decreasing as the temperature increases. This is due to the exponential rise of the vapor pressure curve which makes the permeate flux increases substantially as the temperature rises. These larger mass fluxes involve more important heat fluxes through the liquid phases, increasing the temperature gradient in the liquid boundary layers and so the temperature polarization. For this reason $J$ does not increase with the temperature as fast as the vapor pressure does.

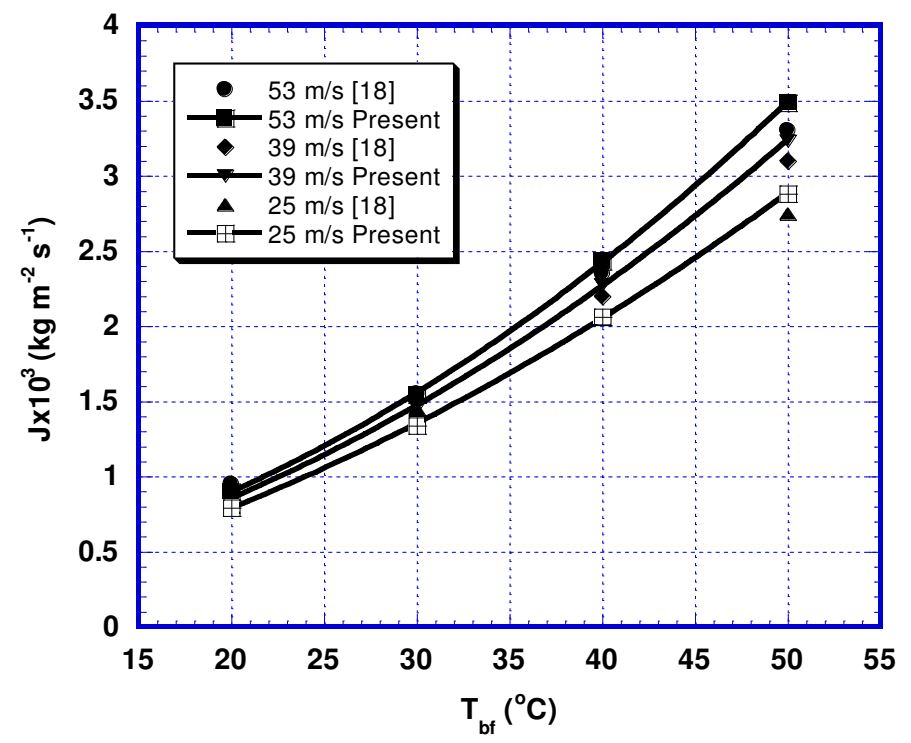

Fig. 2 Water flux vs. feed temperature for feed/permeate inlet velocity of 25,39 and 53 $\mathrm{m} / \mathrm{s}$. For both the present study and the experiment $\Delta T_{b}=10^{\circ} \mathrm{C}$.

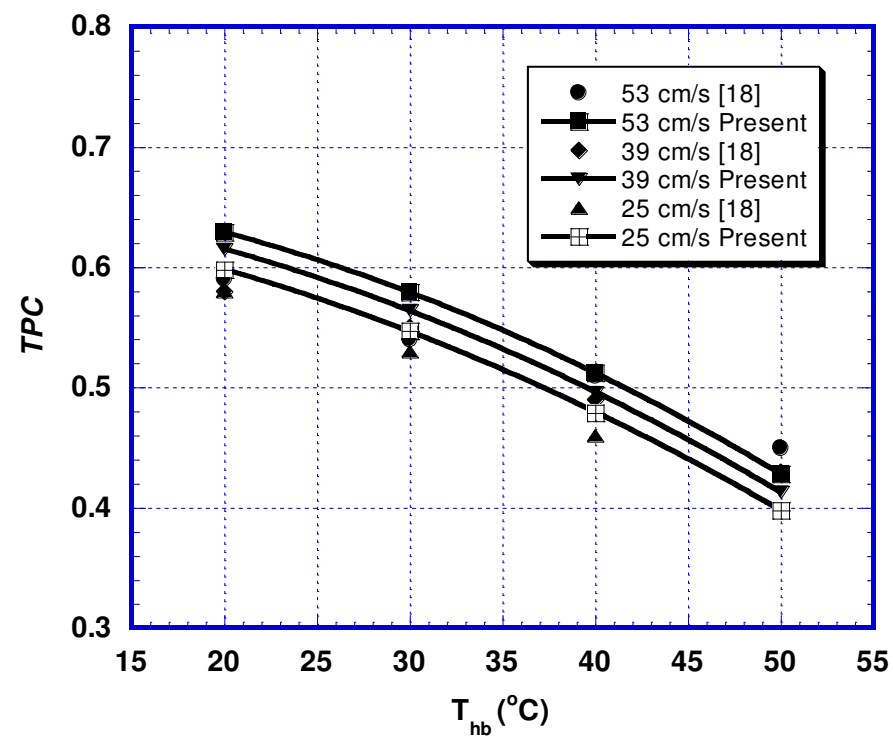

Fig. 3 Temperature polarization coefficient vs. feed temperature for feed/permeate inlet velocity of 25,39 and $53 \mathrm{~m} / \mathrm{s}$. For both the present study and the experiment $\Delta T_{b}=$ $10^{\circ} \mathrm{C}$. 


\subsection{Model Predictions}

In the present study, series of simulations were carried out to examine the predictability power of the present model for the DCMD concentration processes of cane-sugar syrup. Numerical simulations are performed to study the effects of varying the controlling parameters such as the cane-sugar syrup feed temperature and concentration on the performance of the DCMD processes. The analysis is made for the inlet temperature of the feed solution $\left(T_{\mathrm{hi}}\right)$ in the range of $55-75^{\circ} \mathrm{C}$ at $5^{\circ} \mathrm{C}$ increments, feed solution inlet cane-sugar syrup concentrations of $10-20^{\circ} \mathrm{Brix}$ at $5^{\circ} \mathrm{Brix}$ increments, feed solution flow rates $\left(V_{\mathrm{hi}}\right)$ of $1000-2500 \mathrm{ml} / \mathrm{min}$ at $500 \mathrm{ml} / \mathrm{min}$ increments. The cold solution flow rate $\left(V_{\mathrm{ci}}\right)$ of $500 \mathrm{ml} / \mathrm{min}$, and inlet temperature $\left(T_{\mathrm{ci}}\right)$ of $25^{\circ} \mathrm{C}$ are kept constants through this study. The membrane employed in the present study is the same as the one used in the validation step.

\subsubsection{Velocity, temperature and concentration profiles}

In order to demonstrate that the developed model is capable of predicting physically realistic distributions of the quantities of interest, namely velocities, temperature and concentration, simulation runs were performed. The flow, temperature, and concentration profiles results were obtained for temperature difference of $50^{\circ} \mathrm{C}$, feed concentration of $20^{\circ} \mathrm{Brix}$, and feed flow rate $V_{h}$ of $1000 \mathrm{ml} / \mathrm{min}$. The feed flow rate $V_{h}$ is calculated as the feed velocity multiplied by the cell area perpendicular to the liquid flow direction. Examples of the computed results for fields of streamwise velocity, temperature, and concentration are shown in Figs. 4-7.

For the case under study, velocity profiles in the hot solution at different values of $x / L$ are shown in Fig. 4 at $x / L=0,0.5$, and 0.9. The figure shows the boundary layers growth along the channel, with the boundary layer thickness near the membrane wall decreasing from $x / L=0$ to 0.9 . This could be attributed to the mass permeation from the hot channel to the cold channel through the membrane as a result of temperature difference.

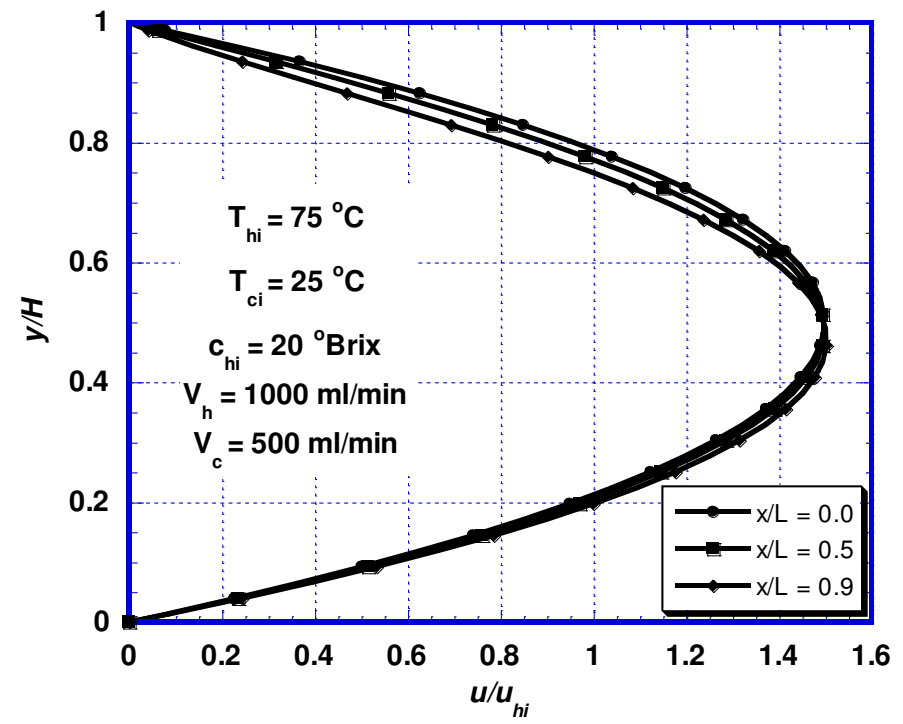

Fig. 4 Streamwise velocity profiles at different axial position along hot channel. 
Similarly, the local temperature profiles $T(x=$ constant, $y$ ) along the $y$ coordinate will vary remarkably from $x / L=0.1$ to 0.9 as shown in Fig. 5. Figure 5 shows an example of the temperature profiles obtained numerically in the present study at different axial positions in the feed channel. Also the profiles in the hot and cold channels are very similar (not shown). The plotted values are referred to the corresponding local temperature on the membrane hot surface $\left(T_{m}\right)$. When this figure is observed, important temperature drops in the thermal boundary layers can be seen. Taking into account that in this case the whole bulk temperature drop through the hot channel, was about $20^{\circ} \mathrm{C}$ (as shown in Fig. 6), temperature drops in each thermal boundary layers ranging from 1.6 (corresponding to the axial location of $x / L=0.1$ ) to $4.8^{\circ} \mathrm{C}$ (for the axial location of $x / L=0.9$ ) are indicative of important temperature polarization phenomena in the system studied.

Figure 6 shows the dependence of the feed and cold solutions temperature at the surface of the membrane on the distance from the channel inlet. The figure also shows the axial distribution of the bulk temperatures in the feed and cold channels for the case considered (concentration of $20^{\circ} \mathrm{Brix}$, temperature difference of $50^{\circ} \mathrm{C}$ and hot feed flow rate of $1000 \mathrm{ml} / \mathrm{min}$ ). The results shown in the figure reflect the characteristic temperature distribution of a countercurrent flow heat exchanger. In a relatively short entrance region, the transmembrane water flux is very high due to the large driving force. This high flux leads to steep drop of the surface temperature, as it can be seen in the figure. Results obtained in the present study show that the temperature gradients are built along $\mathrm{x}$ coordinate in the flow direction inside both the feed and permeate channels.

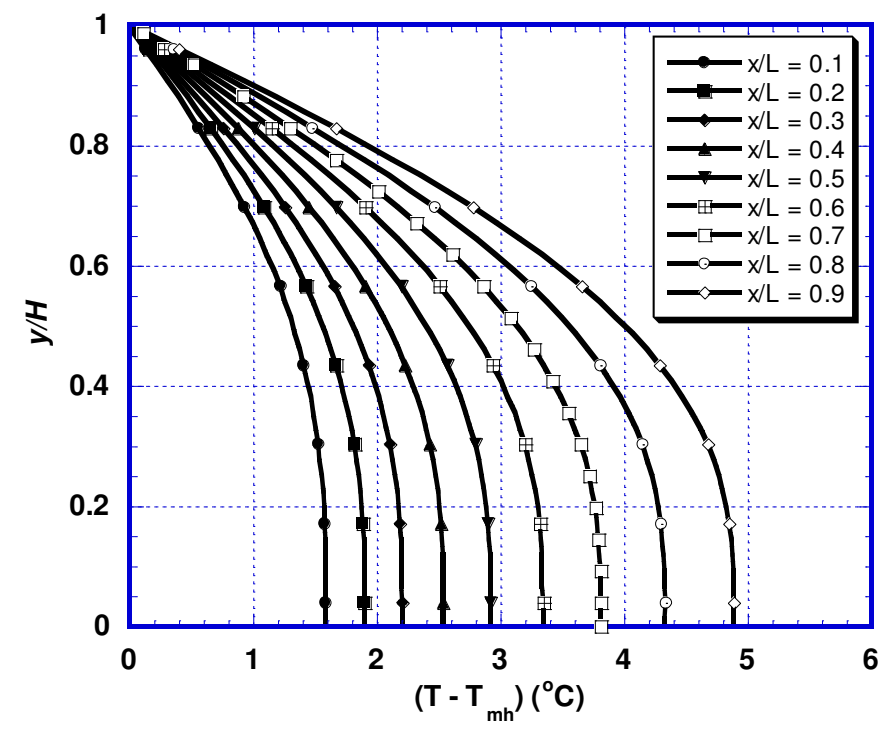

Fig. 5 Temperature profiles at different axial position along the hot channel

Figure 7 shows an example of the concentration polarization distribution obtained numerically in the present study at different axial positions in the feed channel for the case considered (concentration of $20^{\circ} \mathrm{Brix}$, temperature difference of $50^{\circ} \mathrm{C}$ and hot feed flow rate of $1000 \mathrm{ml} / \mathrm{min}$ ). It is obvious from the figure that the hot 
solution concentration is increased as flow goes downstream in the channel due to the pure water permeation through the membrane as a result of temperature difference between the hot and cold streams. The concentration at the vicinity of the membrane wall increases as the flow moves downstream suggesting that the species convection towards the wall is much larger than the species diffusion away from the wall. This concentration build up near the membrane wall will adversely affect the driving force of membrane distillation as can be seen later.

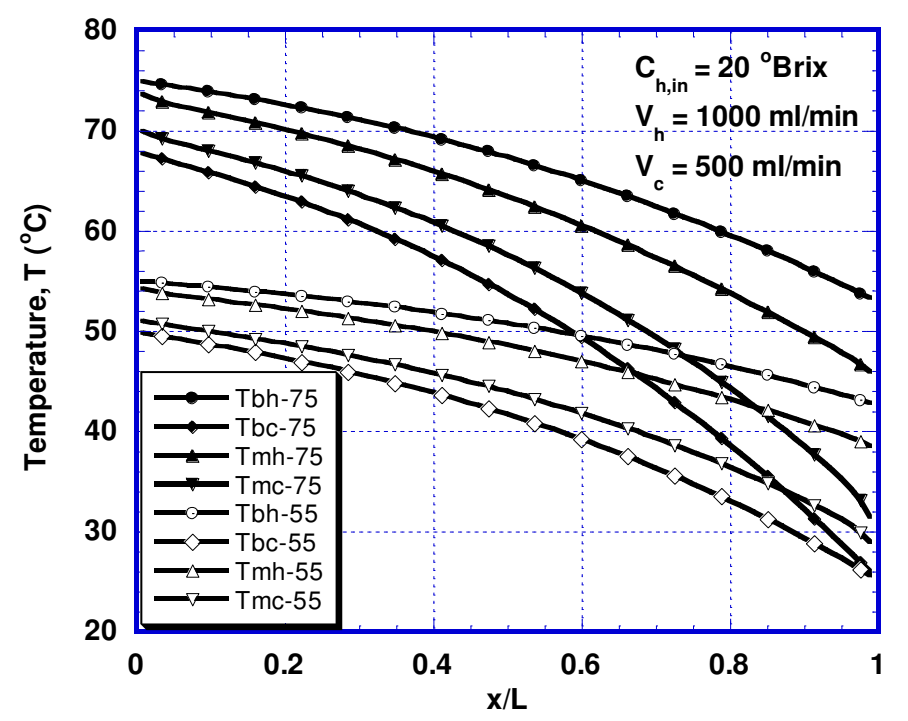

Fig. 6 Axial distributions of hot and cold streams bulk/wall temperatures.

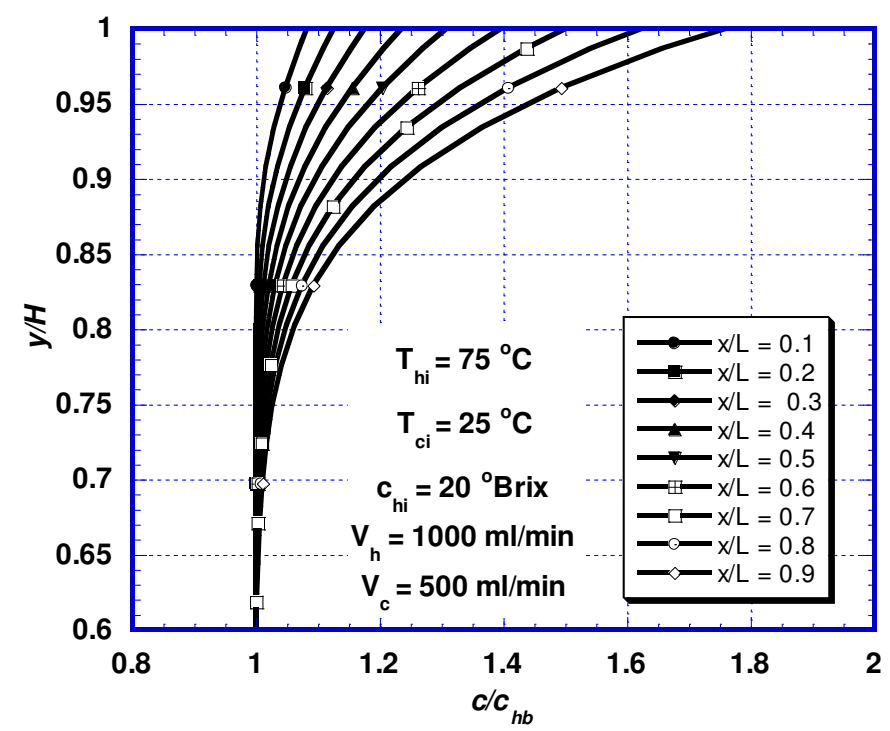

Fig. 7 Concentration polarization profiles at different axial position along hot channel 


\subsubsection{Effect of feed temperature and concentration on the DCMD}

The operating parameters that impact DCMD performance are feed and permeate temperatures and flow rates (which impact the heat transfer coefficients). For example, performance (evaluated in terms of the flux) improves monotonically as the feed temperature is increased from its lower limit of $0^{\circ} \mathrm{C}$ to its upper limit of $100^{\circ} \mathrm{C}$ (limits for MD of dilute aqueous solutions) [19]. Feed and permeate flow rates exhibit similar influence [19].

Computer simulations used to investigate the influence of $\Delta T$, the difference between feed and permeate temperatures, for a specific case of DCMD performance are reported here. Figure 8 shows the distillate fluxes as a function of the average temperature differences when different feed cane-sugar syrup concentrations in the membrane module are considered. Figure 8 shows that the permeation flux at different values of $\Delta T$ at constant permeate temperature of $25^{\circ} \mathrm{C}$ is increased as $\Delta T$ is increased. A non-linear increase in the flux with increasing temperature reflects the exponential increase in the vapor pressure which provides the driving force. Figure 8 also shows that the flux decreases in an approximately linear way with the feed concentration in the studied range. This can be attributed to the fact that the permeation driving force (vapor pressure) is increased as $\Delta T$ is increased and decreased as the feed concentration is increased. These results agree very well with the experimental results of Nene et al. [20].

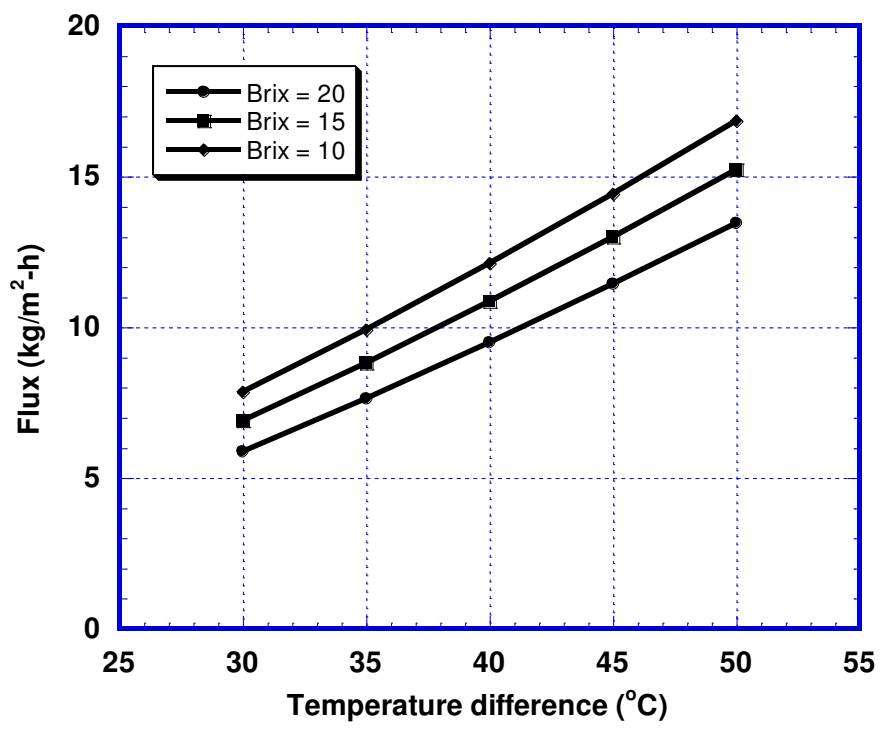

Fig. 8 Membrane distillation of cane-sugar syrup for various values of $\Delta T$ (at constant cold side temperature of $25^{\circ} \mathrm{C}$ )

\subsubsection{Effect of feed flow rate on the DCMD}

The variation of permeate flux for different values of feed flow rate $V_{h}$ is shown in Fig. 9. It has been noted that as the feed flow rate increase, the permeate flux increases. The permeate fluxes increase with feed flow rate, and they seem to reach maximum values 
asymptotically for higher feed flow rate. Figure 9 shows that the permeate flux increases with the recirculation rate. This can be attributed to the fact that increasing the recirculation rate is to increase the heat transfer coefficient and thus reduce the effect of temperature polarization (TPC is increased with $V_{h}$ ). This means that the temperatures at the membrane surface more closely approximate that of the bulk streams, and thus the trans-membrane temperature difference is greater. This produces a greater driving force and consequently enhances the flux.

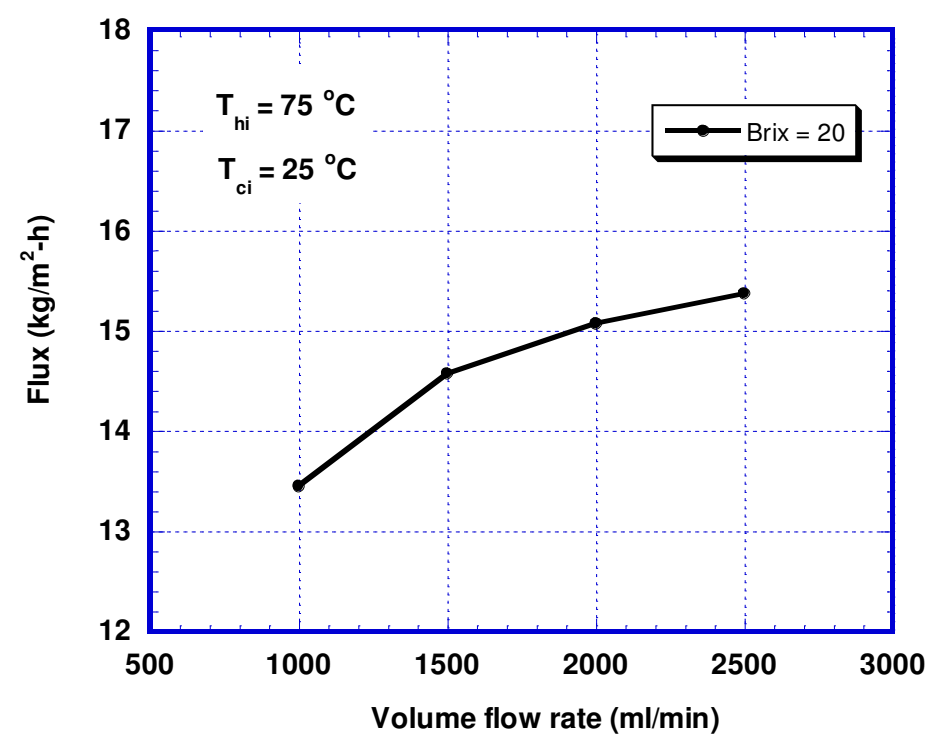

Fig. 9 Membrane distillation of cane-sugar syrup for various feed flow rates.

\subsubsection{Temperature and concentration polarization coefficients}

A commonly used measure of the magnitudes of the boundary layer heat transfer resistances relative to the total heat transfer resistance of the system is given by the temperature polarization coefficient: $T P C$ given by Eq. (21). The value of $T P C$ approaches unity for well designed systems, and it approaches zero for systems that are hampered by large boundary layer resistances (high degrees of temperature and concentration polarization) [18]. The highest values [18] of TPC reported in the literature for pure water DCMD fall within a range of 0.4 (high fluxes) to 0.7 (low fluxes). Figure 10 shows the calculated values of TPC for the cane-sugar syrup DCMD results described above. At very low $T_{h i}$ (low flux), TPC ranges from 0.5264 for the $20^{\circ} \mathrm{Brix}$ feed to 0.4496 for the $10^{\circ} \mathrm{Brix}$ feed. Even at higher $T_{h i}$ (high flux), the value of TPC still lies above the 0.35 value.

As indicated previously after evaluating $T P C$ we have evaluated the concentration polarization from the Eq. (21). It was calculated that the membrane wall concentration was as far as $8 \%$ higher than the bulk concentration $\left(c_{m} / c_{b h}=1.04\right)$ as shown in Fig. 7. In the present study, this concentration increase means a decrease of the vapor pressure to about $0.3 \%$. As a consequence of the concentration polarization leads to a negligible reduction in the permeate flux in the studied cases. This is an important result as concentration polarization is a major cause of flux reduction in 
other membrane processes such as ultrafiltration. In the present study, CPC is increased linearly with feed temperatures as shown in Fig. 11.

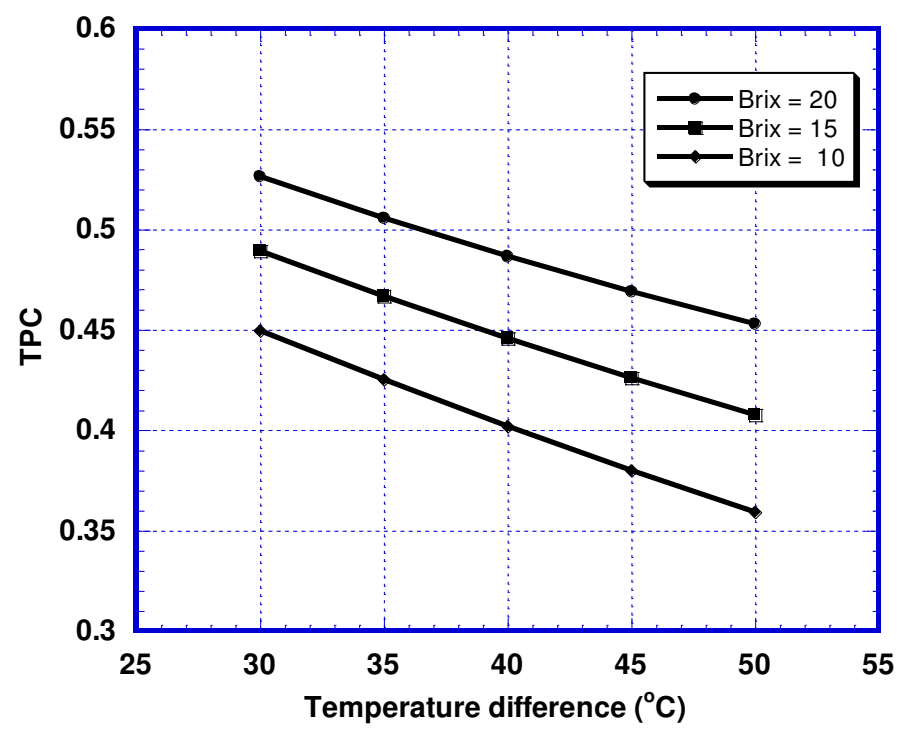

Fig. $10 T P C$ for various feed concentrations.

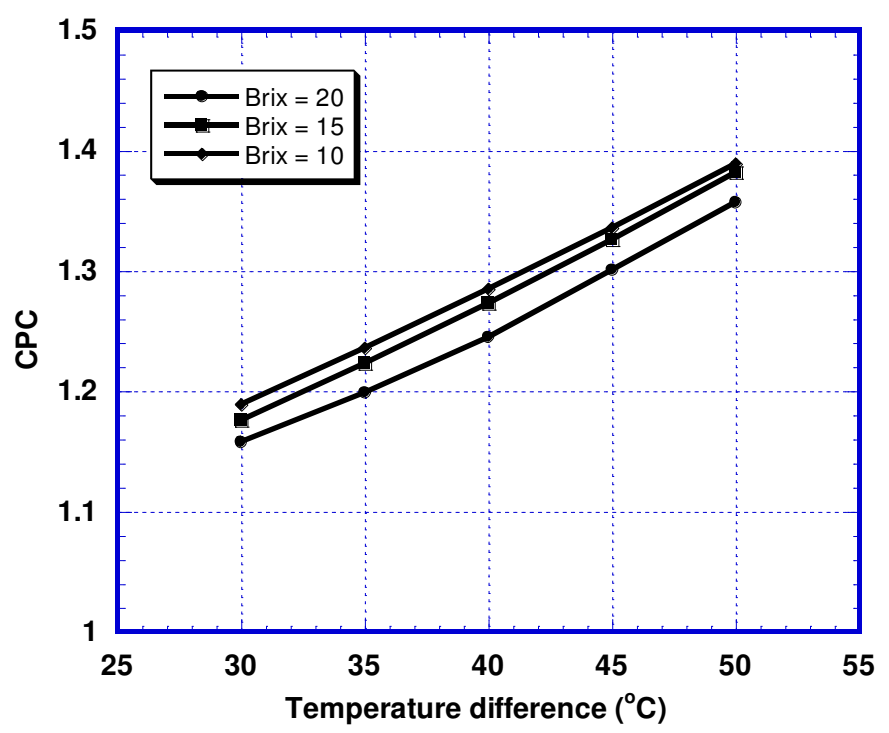

Fig. $11 C P C$ for various feed concentrations.

\subsubsection{Thermal efficiency}

One of the primary concerns in DCMD, with regard to effective energy consumption, is limiting the amount of heat lost in the process. The amount of heat that is lost by conduction through the membrane and the membrane module is a function of the 
module design and the thermal conductivities of the module material and the membrane.

In order to estimate the heat lost, calculations were performed in the following way. The latent heat of evaporation is the heat used effectively and is obtained from the permeate flux. The increase in heat of the cooling water is a sum of the latent heat of evaporation and the conduction heat lost through the membrane from the feed to cooling water. Figure 12 shows the effect of the hot and cold solution inlet temperatures on the thermal efficiency. The thermal efficiency increases by about 11 , 12 , and $13 \%$ as $\Delta T_{\text {hi }}$ increases from 30 to $50^{\circ} \mathrm{C}$ for feed concentration of 10,15 , and $20^{\circ}$ Brix; respectively. Increasing the inlet temperature of the hot solution thus does not only increase the permeate flux but also improves the thermal efficiency.

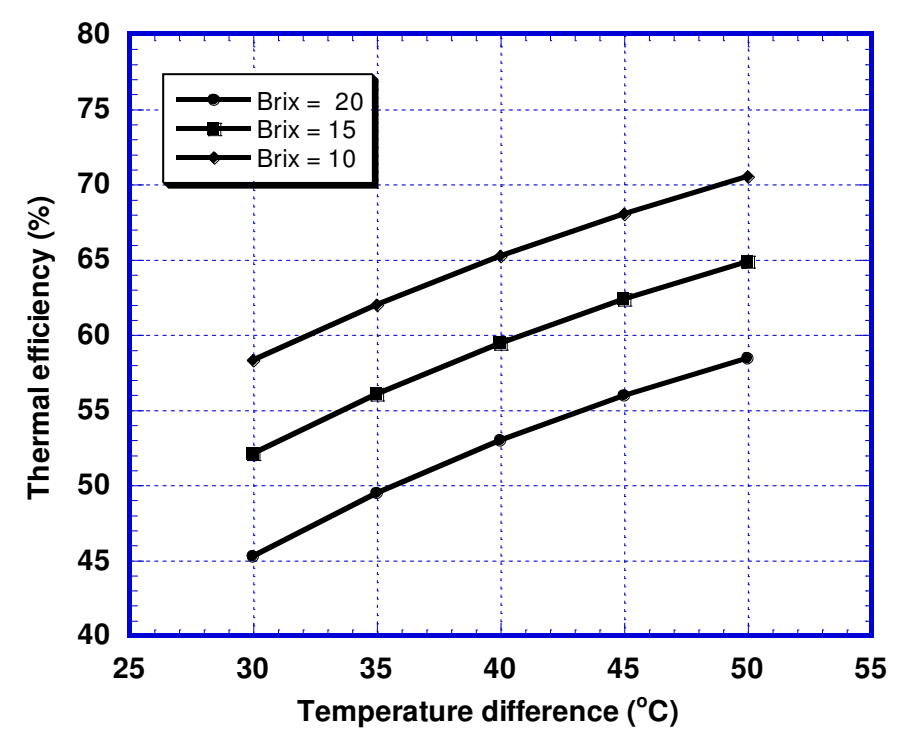

Fig. 12 Thermal efficiency for various feed concentrations.

\section{CONCLUSIONS}

DCMD process has been numerically investigated. This was facilitated by solving the elliptic type of the governing equations using the SIMPLE pressure-correction algorithm for pressure field in connection with the high order QUICK scheme. The alternating direction implicit ADI scheme, which makes use of the TDMA in solving the resulting coefficient matrix, was used to solve the governing equations to reduce the number of iterations. A scheme to secure the overall mass conservation was also employed.

The results obtained in the present study (e.g. Fig. 9) indicate that it was possible to consistently remove water from the cane sugar solution at a steady state value approximating $15.0 \mathrm{~kg} / \mathrm{m}^{2} / \mathrm{h}$. The viscosity of the cane sugar solution at high concentration induces high polarization phenomena. The proposed method succeeds in predicting the effects of the controlling parameters on the DCMD performance. The following points can be drawn from the numerical simulation: 
(1) Difference of temperatures between hot and cold solutions is important factor for the capacity of direct contact membrane distillation process. The distillate flux increases with increasing the temperature difference,

(2) The distillate flux decreases as the feed initial concentration increases,

(3) The distillate flux increases with the flow rate through the feed channel,

(4) The process thermal efficiency enhanced as the feed temperature is increased.

(5) The influence of temperature polarization on the effectiveness of DCMD in cane sugar solution concentration has been found to be important.

The results were compared with the available data and the agreement is satisfactory. This study can be used for DCMD process improvement and optimization.

\section{REFERENCES}

[1] Fortunato Laganà, Giuseppe Barbieri, and Enrico Drioli: Direct contact membrane distillation: modeling and concentration experiments, J. of Membr. Sci. 166 (2000) 1-11.

[2] Sergey Gunko, Svetlana Verbych, Mykhaylo Bryk, and Nidal Hilal: Concentration of apple juice using direct contact membrane distillation, Desalination. 190 (2006) 117-124.

[3] Hsu S.T., Cheng K.T., and Chiou J.S: Seawater desalination by direct contact membrane distillation, Desalination 143 (2002) 279-287.

[4] Qtaishata M., Matsuura T., Kruczek B., and Khayet M.: Heat and mass transfer analysis in direct contact membrane distillation, Desalination 219 (2008) 272292.

[5] Abdul Aziz A. Abbara: Ph. D. Thesis, Assiut University, Assiut, Egypt, 2005.

[6] Sanjay Nene, Suhkvinder Kaur, K. Sumod, and Bhagyashree Joshi: Membrane distillation for the concentration of raw cane-sugar syrup and membrane clarified sugarcane juice, Desalination 147 (2002) 157-160.

[7] Ali K. Abdel-Rahman, Abdul Aziz A. Abbara, and Mohamed R. Bayoumi: Numerical modeling of concentration profiles in membrane channel, J. Eng. Sci., Assiut University 34 (2006) 251-274.

[8] Anderson, D.A., Tannehill, J.C. and Pletcher, R.H.: Computational fluid mechanics and heat transfer, Hemisphere Publishing Corporation, New-York, 1984.

[9] Phattaranawik J., Jiraratananon R., and Fane A.G.: Effect of pore size distribution and air flux on mass transport in direct contact membrane distillation, J. Membr. Sci. 215 (2003) 75-85.

[10] Martinez-Diez L., Vazquez-Gonzalez M.I., and Florido-Diaz F.: Study of membrane distillation using channel spacers, J. Membr. Sci 144 (1998) 45-56.

[11] Ali K. Abdel-Rahman: Ph. D. Thesis, Kyoto University, Kyoto, Japan, 1992.

[12] Geraldes, V., Semião, V. and Pinho, M. N. de: Numerical modeling of mass transfer in slits with semi-permeable membrane walls. Engineering Computations, 17 (2000) 192-217. 
[13] Ali K. Abdel-Rahman, and Suzuki, K.: Laminar channel flow with fluid injection accounting for the flow in the porous wall, Proceedings of the $5^{\text {th }}$ Int. Conference of Fluid Mechanics, Cairo, (1995), 367-379.

[14] Geraldes, V., Semião, V. and Pinho, M.N.de, Flow and mass transfer modeling of nanofiltration. J Membr. Sci. 191 (2001) 109-128.

[15] Partakar, S. V. and Spalding, D. B.: A calculation procedure for heat, mass and momentum transfer in three-dimensional parabolic flows. Int. J Mass and Heat Transfer, 15 (1972) 1787-1806.

[16] Bubnic, Z., Kadlec, P., Urban, D. and Bruhns, M.: Sugar technologists' manual-chemical and physical data for sugar manufactures and users, Bartens, Berlin, Germany, 1995.

[17] EL-Dessouky H.T. and Ettouney H.M.: Fundamentals of salt water desalination, Elsevier, Amsterdam, 2002.

[18] Martinez-Diez L., and Vazquez-Gonzalez M.I.: Temperature and concentration polarization in membrane distillation of aqueous solutions, J. Membr. Sci 156 (1999) 265-273.

[19] Kevin W. Lawson, and Douglas R. Lloyd: Membrane distillation. II. Direct contact MD, J. Membr. Sci 120 (1996) 123-133.

[20] Sanjay Nene, Suhkvinder Kaur, K. Sumod, Bhagyashree Joshi, and K.S.M.S. Raghavarao: Membrane distillation for the concentration of raw cane-sugar syrup and membrane clarified sugarcane juice, Desalination 147 (2002) 157160. 


\title{
نمذجة عملية تركيز عصير قصب السكر الخام باستخذام التقطير بأغثية الاتصال
}

\author{
(المباشر (DCMD) \\ على كامل عبد الرحمن \\ قسم الهندسة الميكانيكية - كلية الهندسة علية لرحنة
}

التقطير بالأغشية هي تقنية واعدة لإجراء عمليات الفصل التي كانت تتم عادة باستخدام عمليات الفصل

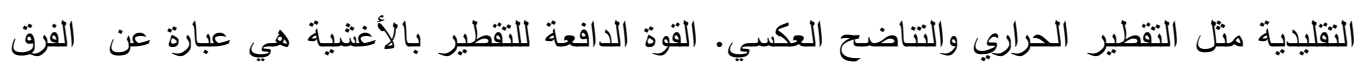
في ضغط البخار الذي يمكن الحصول عليه من خلال وجود محلول عند درجة حرارة أقل من درجة لئل

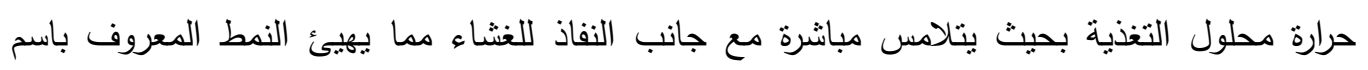
التقطير بأغشية الاتصال المباشر (DCMD). هذه العملية تنواءم بمثالية مع عمليات نركيز المحاليل المخففة مثل عصائر الفاكهة والمحاليل السكرية. تم إجراء الدراسة العددية الحالية من اجل شرح كيفية نطبيق تقنية التقطير بأغثية الاتصال المباشر

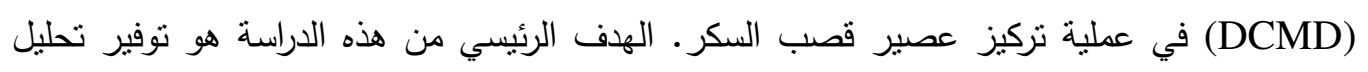

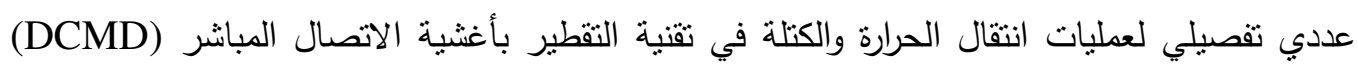
وتوفير معلومات تفصيلية أساسية مفيدة عن طبيعة العملية والتي يحتاج إليها في تحسين وتوفيق العملية.

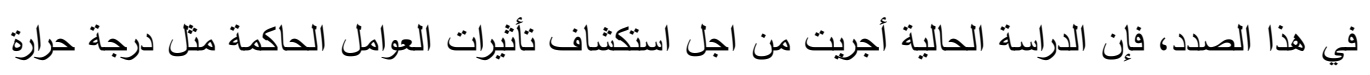

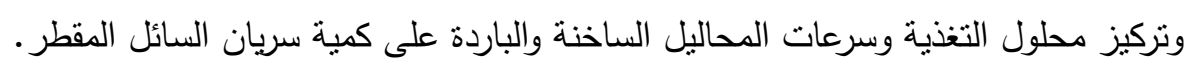

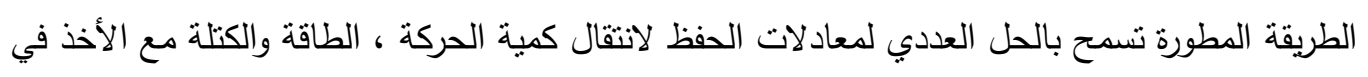

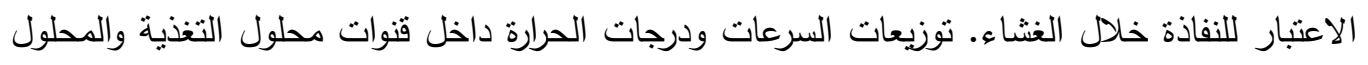

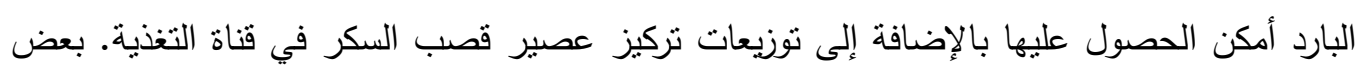

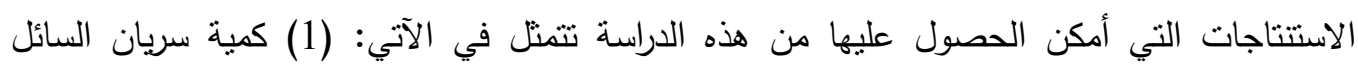

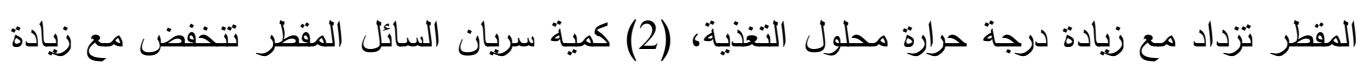
تركيز محلول التغذية، (3) كمية سريان السائل المقطر تزداد مع زيادة معدلات سريان محلول التغذية. نم

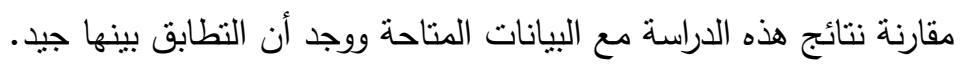

